\title{
A Brief Talk on Information Security Basic Management Work of Intelligent Electric Grid Security Defense System
}

\author{
Dang Fangfang ${ }^{\mathrm{a}}$, Ji Fajia ${ }^{\mathrm{b}}$, Zhu Lei ${ }^{\mathrm{c}}$, Yang Ying \\ Information \& Telecommunication Co. of State Grid Henan Electric Power Company, Zhengzhou, \\ 450052, China \\ aemail: 1365351078@qq.com, bemail:13017698322@wo.cn, cemail:80870176@qq.com
}

Keywords: Basic management, Information security defense system, The close-loop management, Supervision and inspection

\begin{abstract}
With the rapid development of the intelligent electric grid, the information security has been a key factor of the stable operation. It has been urgent that how to optimize the information security defense system on the base of the existing institution mechanism and maintenance framework. This paper has started with the basic management, strengthened the information security basic management, regulated the information security work process, combined the new technology with normal work. It has realized the special work normalization, optimized the close-loop management and constructed a more standard information security management process. Facts show that the failure rate of system has been decreased and the whole level of information network performance and maintenance has been promoted largely.
\end{abstract}

\section{Introduction}

With the rapid development of the intelligent electric grid, the electric grid infrastructure and industrial ecology has been changed. The information security has been the basis of the intelligent electric grid stable operation. At present, the defense technology of the intelligent grid is limited [1][2]. There are such hidden dangers such as information system interrupt, system vulnerability and virus outbreak. At the same time, the threats from users has increased, the external attack methods has been specialized. It has been urgent that how to optimize the information security defense system on the base of the existing institution mechanism and maintenance framework [3].

\section{Strengthen the Information Security Basic Management, Steady the Intelligent Electric Grid Defense System}

Strengthen the information security basic management, carry out the information security governance and promotion deeply. Implement the network security hidden danger rectification and governance, fulfilling the responsibility of the basic units, realize the complete coverage of information security work, improve the level of information security internal management. The information security of Henan company has realized total participation and the management requirements and technology measures has been implemented effectively. According to the annual information security key work, construct supervision and inspection normal mechanism which based on information security internal control. Regulate the information security close-loop management, implement the hierarchy protection, risk evaluation, information security record, security hidden danger inspection and rectification, business authority and permission, weak password governance, security measures optimization and rectification and so on [4]. Carry out a comprehensive governance from information device operation and maintenance to security management. Starting with information security basic management, promote the information security internal work by regulating the management process and strengthening the talent team building. 


\section{Regulate the Information Security Work Process, Strengthen the Close-loop Management}

To ensure all kinds of work can be implemented effectively, Henan company has carded the information security related work process. Aiming at the basic work such as information security record, business authority and permission, account right approval, maintenance account record, hidden danger and vulnerability inspection and supervision, firewall strategy approval and information security test, optimize the work process and regulation. Strengthen the close-loop management and process tracking, improve the level of internal control management, create a good environment for the information security [5].

\section{Develop the Account Right Security Governance Deeply}

The account right security of the information system is the base of carrying out the information security requirements. Combined with the maintenance situation, Henan company adopts the following methods.

Weak Password Governance. Develop the specific weak password governance of the maintenance account. Card the IP address of the systems and fulfill the responsibility. Compile the annual weak password governance plan for business system. Organize the supervise team and maintenance staff, select 3-5 systems to conduct the password inspection monthly. Aiming at the discovered problems, form the corresponding record and definite the rectification time.

Information System Maintenance Account Record. Through formulating the information system maintenance account naming regulation and putting on record to realize the standardized management of maintenance account, decrease the safe risk that because of irregular management. Fulfill the responsibility of each account, perform the approval institution strictly, ensure the account to be real and effective. The maintenance account record process as is shown in Figure 1.

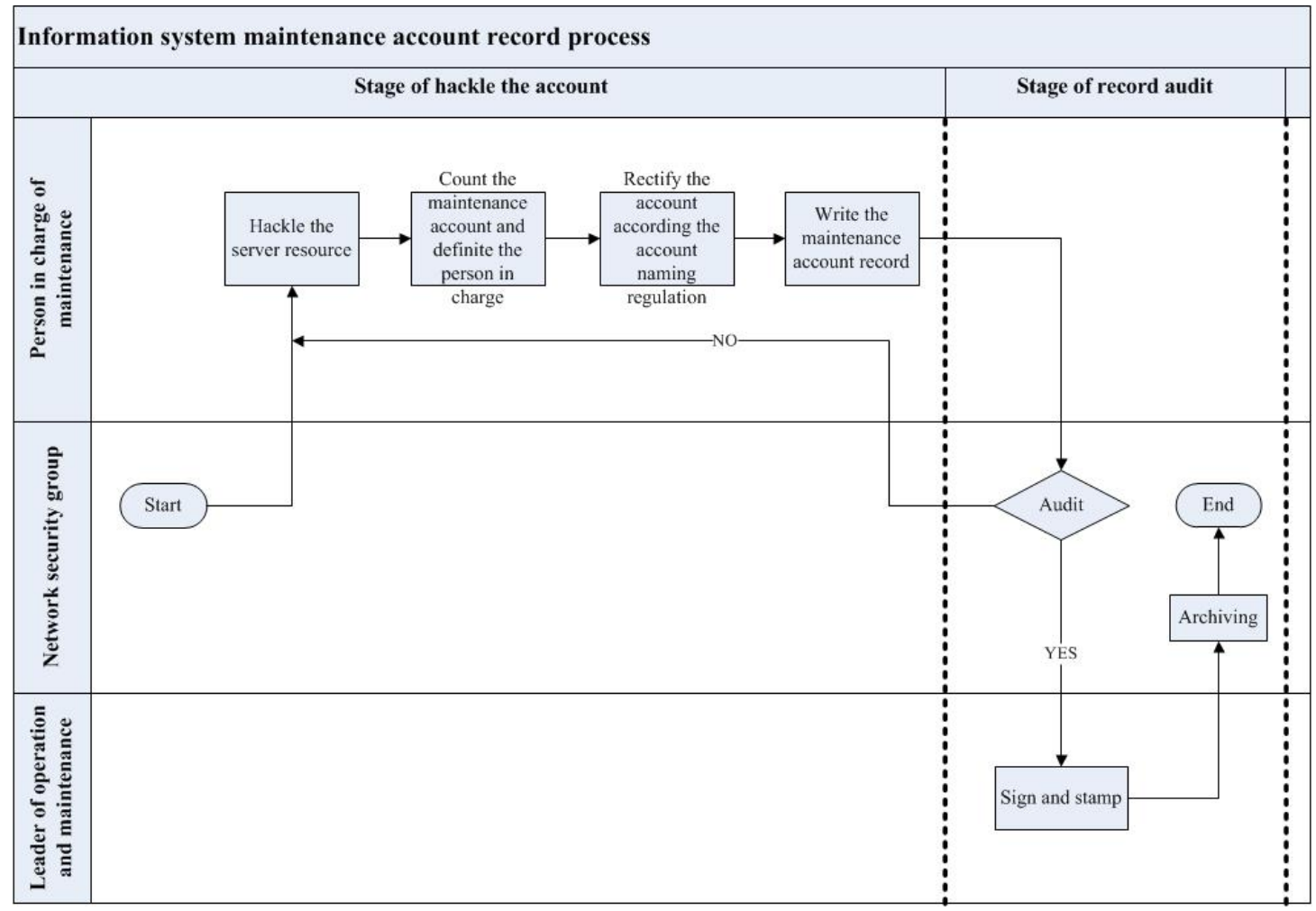

Figure 1.The maintenance account record process

\section{Implement the Internet Website Security Renovation}

Form the specific work group, definite the scope of this renovation. Formulate the work plan and deadline for every work, control the progress assessment strictly, promote this work develop orderly. Close 3 websites, keep 4 internet websites, complete the website hierarchy protection test and 
evaluation, ensure the content of these websites are safe. Strengthen the security control of internet export, optimize the boundary firewall strategy. Organize the "attack-defense" team to conduct the hidden danger inspection and rectification, verify the effectiveness of the key defensive technology measures, ensure the security defense stable and reliable.

\section{Strengthen the Information Security Device Maintenance}

To ensure the minimized service configuration of firewall, Henan company has organized the maintenance staff to hackle the access control strategy and delete the failure strategy.

Export the access control strategy of the intranet boundary firewall and hackle them with the support of supervision team. According to the minimized service configuration principle, optimize the strategy on the base of satisfying the business requirement. Confirm whether the strategy is effective and delete the failure strategy. The approval process of strategy is business application department-> information security personnel-> information security supervision personnel-> information dispatch personnel.

\section{Combine the Technology with Management, Realize the Special Work Normalization}

Aiming at the irregular special inspection, Henan company has combined the self-inspection and rectification with the normal work to realize the special work normalization. For example, under the guide of annual work program, Henan company formulates the sub-program which is about real-name governance, weak password inspection, business authority inspection. Formulate the monthly or quarterly work program to carry out the above work normally. At the same time, utilize the inspection team and its technical strength to carry out the business authority and account right supervision. Organize the related responsible parties to rectify the problems and report the rectified process and measures. Aiming at the typical problem and fault, compile the typical case analysis. All of the above can improve the holistic level of maintenance and efficiency.

\section{Conclusion}

This paper starts with the information security basic management. Through strengthening the information security basic management and regulating the information security work process to optimize the information security management system and decrease the failure rate of Henan company. Facts show that the cost of human resource and maintenance has been decreased and the whole level of information network performance and maintenance has been promoted largely.

\section{References}

[1] Chen Laijun, Mei Shengwei, Chen Ying, The Intelligent Electric Grid Information Security and Its Influence on The Electric System [J]. Control Theory and Application, 2012.

[2] Wang Xiuqing, Wang Suli, The Intelligent Electric Grid Information Security Situation Analysis[J]. Information Technology, 2015.

[3] Gengshen Yu; Qian Guo. Risk-based information security audit applied research in the power industry [C]. Proceedings of 2015 Joint International Mechanical, Electronic and Information Technology Conference(JIMET 2015),2015.

[4] Pan Kejia, The Intelligent Electric Grid Information Security Situation Analysis[J]. Information and Communication, 2013.

[5] Yin Zhiqing, The Electric Enterprise Information Network Security Construction Analysis [J]. The Electric Information, 2013. 